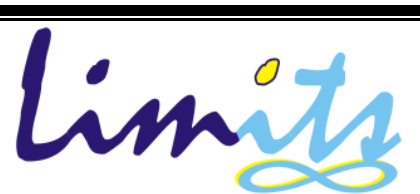

Journal of Mathematics and Its Applications.

E-ISSN: 2579-8936

P-ISSN: $1829-605 \mathrm{X}$

Vol. 16, No. 1, Agustus 2019, 39-49

\title{
Kontrol Optimum pada Model Prey-Predator dengan Pemanenan pada Ikan Prey dan Ikan Predator
}

\author{
Oryza Safitri ${ }^{1}$, Mardlijah ${ }^{2}$ \\ ${ }^{1,2}$ Institut Teknologi Sepuluh Nopember (ITS) \\ Jl. Raya ITS, Keputih, Kec. Sukolilo, Kota Surabaya, Jawa Timur 60111 \\ 1,2 Departemen Matematika Pasca Sarjana, Fakultas Matematika, Komputasi, dan Sains Data \\ e-mail: safitrioryza@ gmail.com ${ }^{1}$, mardlijah@ matematika.its.ac.id ${ }^{2}$
}

\begin{abstract}
Abstrak
Model prey-predator didasari oleh hubungan interaksi predasi antara suatu organisme yang memakan suatu organisme lainnya, dalam kasus ini yaitu ikan prey dan ikan predator. Selanjutnya diberi perlakuan pemanenan pada ikan prey dan ikan predator. Untuk menjaga agar tindakan pemanenan tidak mengakibatkan kelangkaan suatu jenis ikan, dilakukan kontrol optimum berupa penambahan makanan lain pada ikan predator. Kontrol optimum ini dimaksudkan agar hasil pemanenan yang didapatkan maksimal sekaligus menjaga keberlangsungan ekosistem pada ikan prey dan ikan predator. Kemudian didapatkan titik-titik ekuilibrium dengan satu titik ekuilibrium yang stabil yaitu di titik (75.39, 4.20). Selanjutnya hasil kontrol optimal, populasi ikan prey dan ikan predator lebih banyak, dibandingkan populasi ikan prey dan ikan predator sebelum dikontrol.
\end{abstract}

Kata kunci : Model Prey-Predator, Kontrol Optimum, Penambahan Makanan

\begin{abstract}
The pre-predator model is based on the interaction of predation between an organism that eats another organism, in this case the prey and predatory fish. Furthermore, they were given harvest treatment on prey and predatory fish. Extreme harvesting can result in a scarcity offish. So that optimum control is needed in the form of adding otherfoods to predatory fish. This is intended to maximize the yield of harvesting while preserving the ecosystem sustainability of prey and predatory fish. Then the equilibrium points are obtained with one stable equilibrium point, namely at the point $(75.39,4.20)$. Furthermore, the results of optimal control, prey and predatory fish populations were higher, compared to prey and predatory fish populations before being controlled.
\end{abstract}

Keywords: Prey-Predator Model,Optimum Control, Additional Food

\section{Pendahuluan}

Ekosistem merupakan sistem ekologi yang terbentuk oleh hubungan timbal balik antara mahluk hidup dengan lingkungannya. Suatu tingkatan organisasi dikatakan sebagai suatu sistem karena memiliki komponen-komponen dengan fungsi berbeda yang terkoordinasi secara baik sehingga masing-masing komponen terjadi hubungan timbal balik. Hubungan timbal balik terwujudkan dalam rantai makanan [1]. Rantai makanan terjadi karena adanya interaksi antar mahluk hidup. Bentuk interaksi pada rantai makanan salah satunya yaitu predasi (mangsa- 
pemangsa). Predasi adalah bentuk interaksi antara suatu organisme yang memakan suatu organisme lainnya pada suatu tempat tertentu. Dalam matematika, suatu bentuk interaksi predasi dimodelkan sebagai model prey-predator.

Model prey-predator adalah model matematika dengan asumsi bahwa adanya interaksi predasi antara predator sebagai organisme pemangsa dan prey sebagai organisme yang dimangsa. Dalam model prey-predator yang diberi perlakuan pemanenan biasanya banyak terjadi pada ekosistem perairan dengan ikan berukuran besar yang menjadi pemangsa (predator) dan ikan berukuran kecil yang dimangsa (prey).

Dalam memenuhi kebutuhan hidup, manusia aktif melakukan ekploitasi pada segala bidang, termasuk pada pemanenan. Khususnya nelayan sebagai mata pencaharian, aktif melakukan pemanenan pada ikan. Pada umumnya nelayan memanen lebih dari satu jenis ikan. Namun ekosistem perairan sering kali terganggu dengan kegiatan ekploitasi manusia yang berlebihan. Pemanenan ikan yang berlebihan dapat menyebabkan kelangkaan bahkan punahnya suatu spesies ikan. Sehingga menjaga keberlangsungan ekosistem perairan sekaligus dapat memenuhi kebutuhan hidup manusia dari kedua pemanenan tersebut adalah sangat penting. Oleh karena itu, dalam penelitian ini akan dilakukan optimal kontrol pemanenan ikan prey dan ikan predator pada model prey-predator.

Beberapa penelitian yang telah dilakukan terhadap sistem prey-predator, yaitu penelitian [2] tentang analisis model mangsa-pemangsa Michaelis-Menten dengan pemanenan konstan pada populasi prey. Penelitian [3] tentang Effort Dynamics in a Prey-Predator Model with Hervesting. Pada penelitian tersebut membahas kestabilan model prey-predator dengan perlakuan pemanenan pada prey dengan kontrol optimal. Penelitian selanjutnya [4] tentang Analisis Kestabilan Model Prey-Predator dengan pemanenan konstan pada ikan prey. Pada penelitian tersebut membahas analisis kestabilan model prey-predator dengan perlakuan pemanenan konstan pada ikan prey. Penelitian lainnya [5] tentang Analisa Kestabilan dan Kendali Optimal Pada Model Pemanenan Prey-Predator dengan Fungsi Respon Tipe III. Penelitian selanjutnya juga penelitian [6] tentang Kendali Optimal pada Sistem Prey-Predator dengan Pemberian Makanan Alternatif pada Predator. Model Prey-Predator dalam paper tersebut kondisi kematian predator disebabkan karena perebutan makanan sesama predator diabaikan.

\section{Metode Penelitian}

Penelitian ini dilakukan dengan didahului penentuan titik ekuilibrium dari model matematika prey-predator. Dilanjutkan dengan uji stabilitas titik ekuilibrium dengan cara 
memasukkan nilai titik ekuilibrium ke dalam matriks Jacobian yang diikuti pencarian nilai eigen dari matriks tersebut untuk menentukan kestabilannya. Selanjutnya ditentukan model fungsi objektif dari model prey-predator. Berikutnya dilakukan perhitungan kontrol optimal berdasarkan fungsi objektif yang diperoleh dilanjutkan dengan penyelesaian menggunakan prinsip maksimum Pontryagin. Simulasi dilakukan dengan menggunakan perangkat lunak Matlab. Dari hasil simulasi dilakukan analisa untuk mendapatkan simpulan.

\section{Hasil dan Pembahasan}

\subsection{Model Prey-Predator}

Populasi ikan prey $x$ terus tumbuh secara alami dengan laju pertumbuhan sebesar $r$ terhadap $t$ waktu. Sedangkan laju perkapita populasi ikan prey berkurang sebesar $\frac{x}{K}$ untuk setiap bertambahnya ikan prey karena keterbatasan daya dukung lingkungan. Terdapat interaksi antara ikan prey dan ikan predator yang mengakibatkan populasi ikan prey berkurang dengan adanya laju peningkatan relatif akibat predasi, sebanding dengan laju kelahiran populasi ikan prey sebesar $\frac{\alpha}{a+x}$ dan mengakibatkan pula, laju pertumbuhan ikan predator semakin meningkat sebesar $\beta$. Adanya interaksi antara ikan prey dan ikan predator menyebabkan dampak negatif bagi ikan predator karena terjadinya persaingan antar sesama ikan predator dalam memperebutkan makanan, sehingga meningkatkan laju kematian sebesar $\gamma$. Ikan predator mengalami kematian secara alami sebesar $b$ [3]. Selanjutnya diberi perlakuan pemanenan pada ikan prey dan ikan predator, yang dituliskan dalam model prey-predator [3] berikut :

dengan :

$$
\begin{aligned}
\frac{d x(t)}{d t} & =r x(t)\left(1-\frac{x(t)}{K}\right)-\frac{\alpha x(t) y(t)}{a+x(t)}-h_{1} x(t) \\
\frac{d y(t)}{d t} & =\frac{\beta \alpha x(t) y(t)}{a+x(t)}-b y(t)-\gamma y(t)^{2}-h_{2} y(t)
\end{aligned}
$$

$x(t)$ adalah banyaknya populasi ikan prey terhadap $\mathrm{t}$ waktu,

$y(t)$ adalah banyaknya populasi ikan predator terhadap t waktu,

$r$ adalah laju pertumbuhan interistik populasi ikan prey,

$b$ adalah laju kematian alami populasi ikan predator,

$\frac{\alpha}{a+x}$ adalah laju penangkapan relatife maksimum akibat predasi oleh ikan predator,

$\beta$ adalah pertumbuhan populasi ikan predator,

$\gamma$ adalah laju kematian ikan predator akibat perebutan makanan sesame predator,

$\mathrm{K}$ adalah daya kapasitas maksimum populasi ikan prey,

$h_{1}, h_{2}$ adalah konstanta pemanenan

dan $x(t), y(t), r, b, a, \alpha, \beta, \gamma, \mathrm{K}, h_{1}, h_{2}$ adalah parameter positif. 


\subsection{Titik Ekuilibrium}

Dalam proses mencari titik ekuilibrium atau titik setimbang, diperlukan parameterparameter yang didapatkan berdasarkan kondisi dilapangan. Parameter yang digunakan dalam model prey-predator dengan pemanenan konstan pada ikan prey menggunakan parameter dan nilai awal yang dirangkum dalam Tabel 1 [3].

Tabel 1. Nilai Awal yang digunakan

\begin{tabular}{cc}
\hline Variabel & Nilai \\
\hline $\boldsymbol{x}(\boldsymbol{t})$ & 80 \\
\hline $\mathrm{y}(\mathrm{t})$ & 20 \\
\hline
\end{tabular}

Tabel 2. Nilai Parameter

\begin{tabular}{cc}
\hline Parameter & Nilai \\
\hline $\boldsymbol{r}$ & 0.8 \\
\hline $\mathrm{K}$ & 100 \\
\hline $\boldsymbol{\alpha}$ & 0.75 \\
\hline $\boldsymbol{\beta}$ & 0.75 \\
\hline $\boldsymbol{\gamma}$ & 0.08 \\
\hline $\boldsymbol{a}$ & 10 \\
\hline $\boldsymbol{b}$ & 0.001 \\
\hline$h_{1}$ & 0,16 \\
\hline$h_{2}$ & 0,16 \\
\hline
\end{tabular}

Berdasarkan persamaan (1) dan (2) dicari titik ekuilibriumnya dengan $\dot{x}=0$ dan $\dot{y}=0$, lalu subtitusi nilai pada Tabel 1 dan Tabel 2. Selanjutnya didapatkan titik-titik ekuilibrium yaitu: $(0,0),(0,-2.0125),(80,0),(75.39,4.20),(-7.697+8.48 \mathrm{i}, 2.921+7.723 i),(-7.697-7.42 \mathrm{i}, 2.921-$ 7.723i).

\subsection{Menguji Kestabilan Titik Ekuilibrium}

Titik ekuilibrium yang didapatkan pada tahap sebelumnya selanjutnya akan diuji stabilitasnya. Untuk menguji kestabilan titik ekuilibrium, dilakukan pencarian nilai eigen pada setiap titik kestabilan. Tahap pertama dalam mencari nilai eigen adalah menentukan matriks Jacobian berdasarkan persamaan (1) dan (2), yaitu:

$$
A=\left[\begin{array}{cc}
r\left(1-\frac{x}{K}\right)-\frac{r x}{K}-\frac{\alpha y}{a+x}+\frac{\alpha x y}{(a+x)^{2}}-h_{1} & -\frac{\alpha x}{a+x} \\
\frac{\beta \alpha y}{a+x}-\frac{\alpha x y}{(a+x)^{2}} & -b+\frac{\beta \alpha y}{a+x}-2 \gamma y-h_{2}
\end{array}\right]
$$

Kemudian dicari

$$
\operatorname{det}(\lambda I-A)=0
$$


- Untuk titik $(0,0)$ didapatkan nilai $\lambda_{1}=-0.161$ dan $\lambda_{2}=0.64$. Hal ini menunjukkan bahwa di titik ekuilibrium $(0,0)$ tidak stabil dengan jenis kestabilan sadle node.

- Untuk titik $(0,-2.0125)$ didapatkan nilai $\lambda_{1}=0.161$ dan $\lambda_{2}=0.79$. Hal ini menunjukkan bahwa di titik ekuilibrium $(0,-2.0125)$ tidak stabil.

- Untuk titik $(80,0)$ didapatkan nilai $\lambda_{1}=-0.64$ dan $\lambda_{2}=0.339$. Hal ini menunjukkan bahwa di titik ekuilibrium $(80,0)$ tidak stabil dengan jenis kestabilan sadle node.

- Untuk titik $(75.39,4.20)$ didapatkan nilai $\lambda_{1}=-0.56$ dan $\lambda_{2}=-0.345$. Hal ini menunjukkan bahwa di titik ekuilibrium $(75.39,4.20)$ stabil dengan jenis kestabilan stabil asimtotik. Artinya ketika ikan prey sebanyak 75.39 satuan dan ikan predator sebanyak 4.20 satuan, kedua jenis ikan tersebut dapat hidup secara berdampingan.

- Untuk titik $(-7.697+8.48 i, 2.921+7.723 i)$ didapatkan nilai $\lambda_{1}=0.6+0.98 i$ dan $\lambda_{2}=$ $-0.21-0.94 i$. Hal ini menunjukkan bahwa titik ekuilibrium (-7.697+8.48i, $2.921+7.723 i)$ tidak stabil dengan jenis kestabilan sadle node.

- Untuk titik (-7.697-8.48i , 2.921-7.723i) didapatkan nilai $\lambda_{1}=0.6-0.98 i$ dan $\lambda_{2}=$ $-0.21+0.94 i$. Hal ini menunjukkan bahwa titik ekuilibrium (-7.697+8.48i, $2.921+7.723 i)$ tidak stabil dengan jenis kestabilan sadle node.

\subsection{Kontrol Optimal}

Pada sistem diberi perlakuan kontrol berupa pemberian makanan tambahan pada ikan predator. Sehingga pada persamaan (1) dan (2) ditambahkan fungsi kontrol:

$$
\begin{gathered}
\frac{d x(t)}{d t}=r x(t)\left(1-\frac{x(t)}{K}\right)-\frac{\alpha x(t)(1-C) y(t)}{a+x(t)}-h_{1} x(t) \\
\frac{d y(t)}{d t}=\frac{\beta \alpha x(t)(1-C) y(t)}{a+x(t)}+C y-b y(t)-\gamma y(t)^{2}-h_{2} y(t)
\end{gathered}
$$

Daerah penyelesaian pada bidang biologi khususnya pertumbuhan adalah pada kuadran positif yaitu $\mathbb{R}^{2}+$.

\subsection{Penyelesaian Kontrol Optimal}

\section{Fungsi Obyektif}

Pada kontrol yang diterapkan adalah memaksimumkan populasi ikan prey dan ikan predator dan meminimumkan ongkos. Maka fungsi $\mathrm{J}$ adalah:

$$
\operatorname{Max} J=p_{1} x(t)+p_{2} y(t)-p_{3} \int_{0}^{t_{f}} C^{2} d t
$$


Dengan $p_{1}, p_{2}, p_{3}$ adalah konstanta pembobot $C$ adalah variabel ongkos. Dengan syarat batas:

$$
\begin{gathered}
x(0)=x_{0} ; y(0)=y_{0} \\
C_{\text {max }} \leq C \leq C_{\text {min }}
\end{gathered}
$$

\section{Fungsi Hamiltonian}

Berdasarkan fungsi J dan persamaan (1) dan (2) dibuat fungsi Hamiltonian sebagai berikut :

$$
\begin{gathered}
H=-p_{3} C^{2}+\lambda_{1}\left(r x(t)\left(1-\frac{x(t)}{K}\right)-\frac{\alpha x(t)(1-C) y(t)}{a+x(t)}-h x(t)\right)+ \\
\lambda_{2}\left(\begin{array}{c}
\frac{\beta \alpha x(t)(1-C) y(t)}{a+x(t)}+C y-b y(t)-\gamma y(t)^{2} \\
-h y(t)
\end{array}\right)
\end{gathered}
$$

\section{Kondisi Stasioner}

Selanjutnya dicari titik stasioner pada fungsi Hamiltonian berikut:

$$
\frac{\partial H}{\partial C}=0
$$

Didapatkan

$$
C^{*}=\frac{y+\frac{\lambda_{1} \alpha x y}{a+x}-\frac{\lambda_{2} \alpha \beta x y}{a+x}}{2 p_{3}}
$$

Sehingga didapatkan kontrol optimal

$$
C=\left\{\begin{array}{cc}
C_{\text {min }}, & \text { jika } \frac{\partial H}{\partial C}>0 \\
C^{*}=\frac{y+\frac{\lambda_{1} \alpha x y}{a+x}-\frac{\lambda_{2} \alpha \beta x y}{a+x}}{2 p_{3}}, & \text { jika } \frac{\partial H}{\partial C}=0 \\
C_{\text {max }}, & \text { jika } \frac{\partial H}{\partial C}<0
\end{array}\right.
$$

\section{Persamaan State}

Selanjutnya berdasarkan fungsi Hamiltonian, didapatkan persamaan state berikut:

$$
\begin{aligned}
& \dot{x}=\frac{\partial H}{\partial \lambda_{1}}=r x-h_{1} x-\frac{r x^{2}}{K}+\frac{\alpha x(C-1) y}{a+x} \\
& \dot{y}=\frac{\partial H}{\partial \lambda_{2}}=-\frac{\beta \alpha x(C-1) y}{a+x}-b y-\gamma y^{2}-h_{2} y
\end{aligned}
$$




\section{Persamaan Co-State}

Selanjutnya berdasarkan fungsi Hamiltonian, didapatkan persamaan co-state berikut :

$\dot{\lambda}_{1}=-\frac{\partial H}{\partial x}=-\lambda_{1} r+\lambda_{1} h_{1}-\frac{\alpha \lambda_{1} y(C-1)}{a+x}+\frac{2 \lambda_{1} r x}{K}+\frac{\alpha \beta \lambda_{2} y(C-1)}{a+x}+\frac{\alpha \lambda_{1} x y(C-1)}{(a+x)^{2}}-\frac{\alpha \beta \lambda_{2} x y(C-1)}{(a+x)^{2}}$

$\dot{\lambda_{2}}=-\frac{\partial H}{\partial y}=-C+\frac{\alpha \beta \lambda_{2} x(C-1)}{(a+x)}+b \lambda_{2}-h_{2} \lambda_{2}+2 \gamma \lambda_{2} y-\frac{\alpha \lambda_{1} x(C-1)}{a+x}$

\subsection{Hasil Simulasi}

Pada simulasi ini dibuat 3 kondisi. Kondisi pertama ketika tanpa kendali dimana predator tidak diberikan makanan alternatif $(C=0)$, kondisi kedua ketika tanpa kendali dimana predator diberikan makanan alternatif secara penuh $(C=1)$ dan kondisi ketiga ketika dengan kendali dimana predator tidak diberikan makanan alternatif secara penuh $C_{\max } \leq C \leq C_{\text {min }}$.

Kemudian dibandingkan untuk kombinasi beberapa nilai $p_{1}, p_{2}, p_{3}$. Simulasi yang dilakukan menggunakan program DOT cvp dengan aplikasi MATLAB. Berikut kombinasi nilai $p_{1}, p_{2}, p_{3}$.

Berikut simulasi hasil running program:

- Simulasi ke I dengan nilai-nilai parameter $p_{1}=0.04 ; p_{2}=0.05 ; p_{3}=0.05$ yang hasilnya ditunjukkan pada Gambar 1

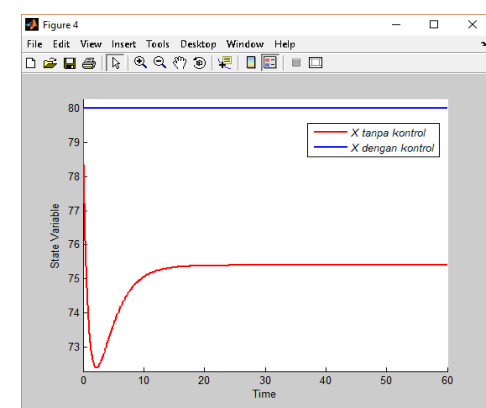

(a) Perbandingan setelah dan sebelum dikontrol ikan prey

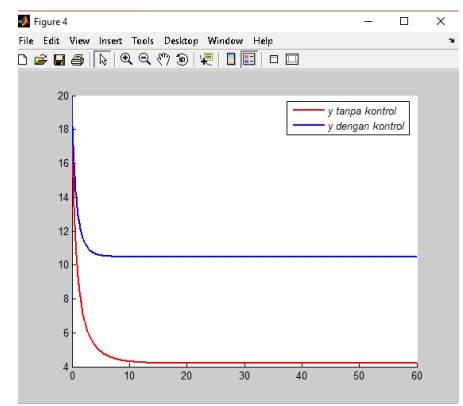

(b) Perbandingan setelah dan sebelum dikontrol ikan predator

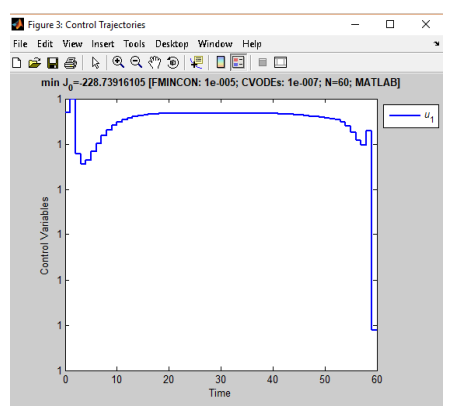

(c) Grafik kontrol terhadap waktu

Gambar 1. Grafik Hasil Simulasi I 
- Simulasi ke II dengan nilai-nilai parameter $p_{1}=0.1 ; p_{2}=0.9 ; p_{3}=0.05$ yang hasilnya ditunjukkan pada Gambar 2

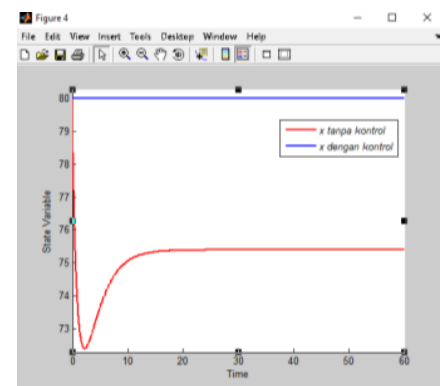

(a) Perbandingan setelah dan sebelum dikontrol ikan prey

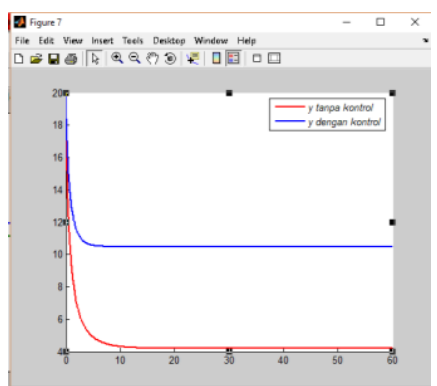

(b) Perbandingan setelah dan sebelum dikontrol ikan predator

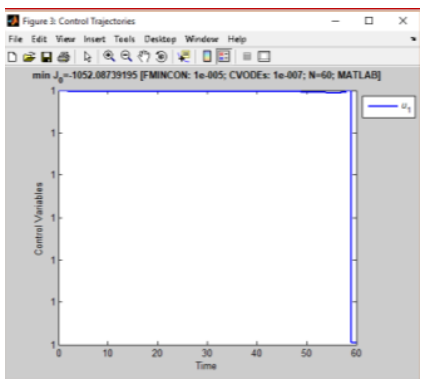

(c) Grafik kontrol terhadap waktu

Gambar 2. Grafik Hasil Simulasi II

- Simulasi III dengan nilai-nilai parameter $p_{1}=0.01 ; p_{2}=0.9 ; p_{3}=0.05$ yang hasilnya ditunjukkan pada Gambar 3

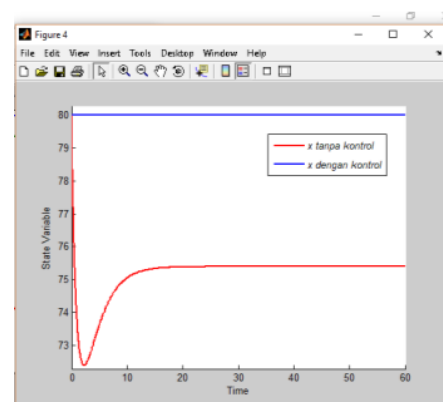

(a) Perbandingan setelah dan sebelum dikontrol ikan prey

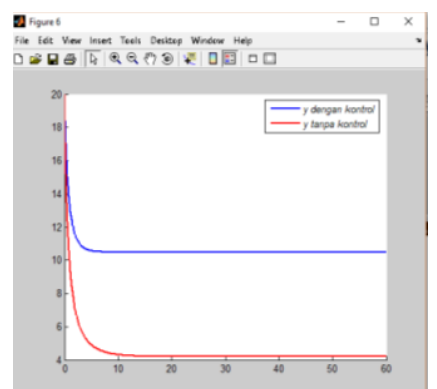

(b) Perbandingan setelah dan sebelum dikontrol ikan predator

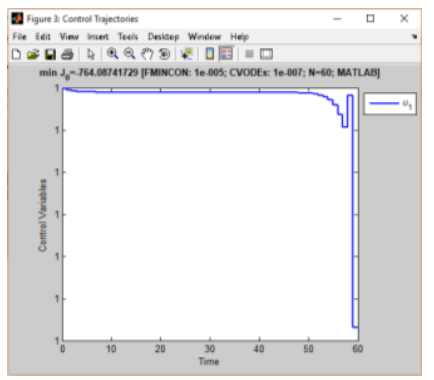

(c) Grafik kontrol terhadap waktu

Gambar 3. Grafik Hasil Simulasi III

Berdasarkan Simulasi I, Simulasi II, dan Simulasi III, didapatkan bahwa nilai $p_{1}, p_{2}, p_{3}$ yang optimum adalah $p_{1}=0,04, p_{2}=0,05, p_{3}=0,05$ dengan hasil $C$ sebesar 228,73 satuan dalam waktu $0<t<60$. Banyaknya ikan prey $x$ dan dan ikan predator $y$ pada setiap kondisi parameter yang berbeda-beda adalah sama. Sementara biayanya semakin tinggi bila konstanta pembobot $p_{2}$, semakin besar. Hal ini disebabkan karena bobot pemberian makanan yang besar, akan menyebabkan biaya yang besar.

Selanjutnya digunakan kondisi paling optimum yaitu simulasi I untuk menunjukkan perubahan populasi ikan prey sebelum dan sesudah dikontrol.

1. Pertumbuhan Populasi Prey

Berikut merupakan grafik populasi ikan prey sebelum dan setelah dikontrol: 


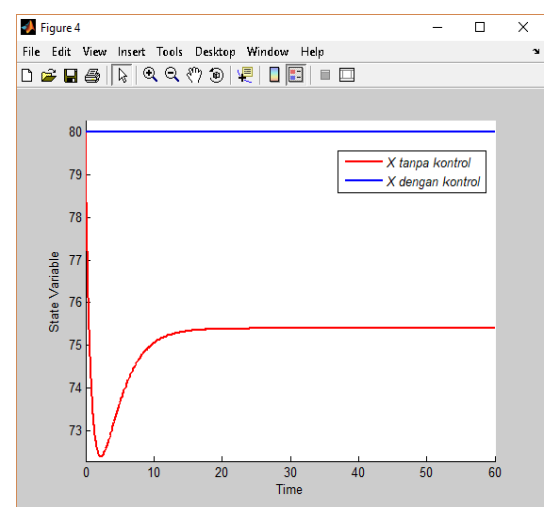

Gambar 4. Grafik Populasi Prey di Semua Kondisi

Berdasarkan Gambar 4, dapat dilihat bahwa ketika $C=0$, faktor laju pertumbuhan intrinsik dan daya dukung lingkungannya lebih besar dari pada faktor predasi dari predator dan faktor upaya pemanenan. Sehingga prey dapat tumbuh dengan baik karena masih didukung oleh tersedianya logistik dan ruang untuk hidup. Sedangkan ketika $C=$ 1, pertumbuhannya meningkat dengan cepat. Hal ini terjadi karena tidak adanya laju predasi predator ke prey serta laju pertumbuhan intrinsik dan kapasitas daya dukung lingkungan yang besar. Hal ini juga disebabkan oleh pemberian makanan tambahan pada ikan predator, sehingga menyebabkan ikan predator mendapatkan pilihan makanan lain. Sehingga mengakibatkan populasi ikan prey meningkat. Secara keseluruhan pertumbuhan populasi ikan prey setelah diberi kontrol berupa pemberian makanan tambahan pada ikan predator, populasi ikan prey lebih banyak atau dapat dikatakan mengalami penambahan.

2. Pertumbuhan Populasi Predator

Berikut merupakan grafik populasi ikan predator sebelum dan setelah di kontrol :

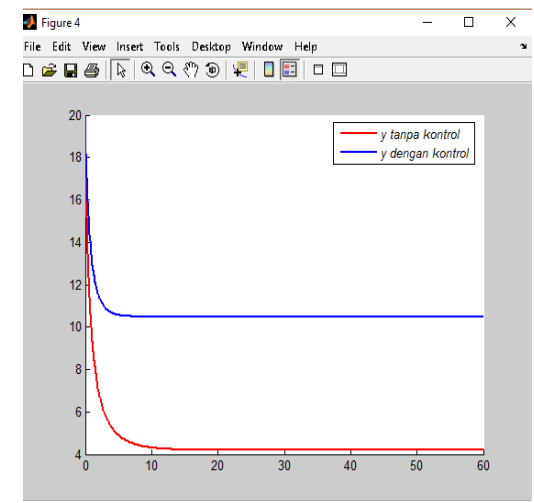

Gambar 5. Grafik Populasi Predator di Semua Kondisi

Berdasarkan Gambar 5, dapat dilihat bahwa ketika $C=0$, pertumbuhan predator menurun. Hal ini terjadi karena jumlah prey yang sedikit dari pada predator 
mengakibatkan kebutuhan predator kurang terpenuhi. Selain itu juga terdapat faktor kematian alami predator serta upaya pemanenan terhadap predator. Sedangkan ketika $C=1$, pertumbuhannya meningkat. Hal ini terjadi karena Adanya makanan tambahan diberikan pada ikan predator, sehingga menyebabkan ikan predator mendapatkan pilihan makanan lain. Melimpahnya makanan ikan predator menjadi faktor utama meningkat populasi ikan predator. Secara keseluruhan pertumbuhan populasi ikan predador setelah diberi kontrol berupa pemberian makanan tambahan pada ikan predator, populasi ikan predator lebih banyak atau dapat dikatakan mengalami penambahan.

3. Pemberian Makanan Tambahan pada Ikan Predator

Untuk mendapatkan populasi prey dan predator yang maksimal maka pemberian makanan alternatif pada predator harus sesuai dengan grafik kendali optimal seperti yang ditunjukkan pada Gambar 6 berikut:

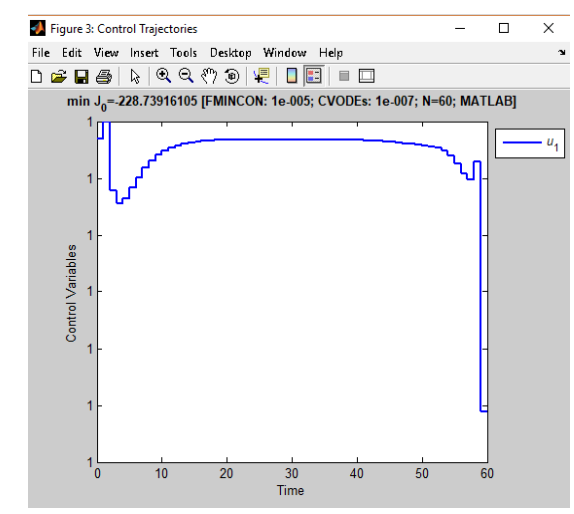

Gambar 6. Grafik Kontrol Optimal Pemberian Makanan pada waktu $0<t<60$

Dari awal hingga waktu 59 satuan, jumlah makanan alternatif yang diberikan sebanyak 1 artinya pemberian makanan diberikan secara penuh. Kemudian diwaktu 59 satuan berangsur menurun hingga waktu 60 satuan. Waktu 60 satuan ke atas tidak diberikan makanan tambahan. Dari perhitungan fungsi obyektif didapatkan bahwa biaya yang dikeluarkan saat diberikan makanan alternatif secara optimal nilainya jauh lebih kecil dari pada saat diberikan makanan alternatif secara penuh. Dan jumlah populasi prey dan predator di waktu awal saat diberikan makanan alternatif secara optimal, nilainya jauh lebih besar dari pada saat tidak diberikan makanan alternatif. 


\section{Simpulan}

Dari penelitian ini dapat disimpulkan bahwa :

1. Analisis kestabilan menunjukkan bahwa terdapat 6 titik kekuilibrium dengan 1 titik yang stabil dengan jenis kestabilan stabil asimtotik, yaitu di titik $(75.39,4.20)$.

2. Berdasarkan kontrol optimal berupa pemberian makanan tambahan, jumlah populasi prey dan predator saat diberikan makanan tambahan secara optimal, nilainya jauh lebih besar dari pada saat tidak diberikan makanan alternatif. Semakin tinggi konstanta pembobot pada ikan predator diberikan, semakin tinggi biayanya.

\section{Daftar Pustaka}

[1] Indriyanto. 2012. Ekologi Hutan: Cetakan ke-4. Jakarta: PT Bumi Aksara.

[2] Dwaradi, H. 2011. Analisis Model Mangsa-pemangsa Michaelis-Menten dengan Pemanenan pada populasi Mangsa. Bogor: Institut Pertanian Bogor.

[3] Kar dan Chakraborty. 2010. Effort Dynamics in a Prey-Predator Model with Hervesting. International Journal of Information and Systems Sciences. Vol. 6 No. 3 pp. 318-332.

[4] Afifah, Luluk Ianatul. 2015. Analisis Kestabilan Predator-Prey dan Model Pemanenan pada Ikan Prey. Malang: Universitas Islam Negeri Maulana Malik Ibrahim.

[5] Rifa'i dan Subchan. 2015. Analisa Kestabilan dan Kendali Optimal pada Model Pemanenan Prey Predator dengan Fungsi Respon Tipe III. Prosiding Seminar Nasional Pendidikan Matematika UMS 2015.

[6] F. Resmi dan Subchan. 2014. Kendali Optimal pada Sistem Prey Predator dengan Pemberian Makanan Alternatif pada Predator, http//digilib.its.ac.id/public/ITS-paper33870-1210100069-paper.pdf. 